\title{
Los arreglos institucionales y la funcionalidad de la democracia
}

\author{
Ma. Amparo Casar*
}

* Catedrático-Investigador del Centro de Investigación y Docencia Económicas (CIDE).

D. R. @ 2012. Universidad Nacional Autónoma de México-Instituto de Investigaciones Jurídicas.

Revista Mexicana de Derecho Electoral, núm. 3, enero-junio de 2013, pp. 147-161, 
El problema de la funcionalidad/efectividad de la democracia ha sido materia de discusión teórica y de la política comparada desde hace décadas. Uno de los estudios de mayor impacto respecto a esta problemática fue el Reporte sobre la Gobernabilidad de la Democracia publicado en 1975. En ese entonces, el pesimismo y la preocupación sobre la situación económica y política en Europa, USA y Japón fue de tal magnitud que se formó un grupo de trabajo - la Comisión Trilateral-para analizar la crisis de la democracia y plantear alternativas de solución. ${ }^{1}$

Se hablaba entonces de una crisis de la gobernabilidad democrática. El diagnóstico era alarmante. Sin ambages se planteaba que la democracia había generado la ruptura de los medios tradicionales de control social, la deslegitimación de las formas de autoridad política y una sobrecarga de demandas sobre el gobierno que excedían su capacidad de responder. Según la Comisión Trilateral, el dilema central de la democracia estaba en el hecho de que las demandas sobre el gobierno democrático crecían mientras su capacidad para satisfacerlas se estancaba.

Ante ello, los autores del reporte se preguntaban si la democracia política, como existía en ese momento, era una forma de gobierno viable para los países industrializados de Europa, Norteamérica y Asia y si estos países podían continuar funcionando durante el último cuarto de siglo con las formas de democracia política que se habían desarrollado en el tercer cuarto de ese siglo.

La conclusión del reporte de la Trilateral fue contundente: Europa, Estados Unidos y Japón pecaban de "exceso de democracia"; la democracia contenía las semillas de su propia destrucción.

Los pronósticos resultaron fallidos. Europa, Estados Unidos y Japón siguen siendo democracias y lejos de acotar lo que entonces llamaron sus excesos surgieron nuevos derechos democráticos y las formas de participación ciudadana se extendieron. Prácticamente ningún país cambió su sistema de gobierno o su sistema electoral. La tesis - sostenida por Huntington - de que "... los problemas de gobernanza sobre todo en Estados Unidos surgían del exceso de democracia" fue derrotada.

1 Crozier, Michael et al., La crisis de la democracia. Reporte sobre la Gobernabilidad de la Democracia a la Comisión Trilateral, Japón, USA y Europa, Nueva York, New York University Press, 1975. 
Sin embargo, las preguntas que entonces se hicieron los integrantes de la Comisión Trilateral han reaparecido una y otra vez. Como botón de muestra basta mirar las consecuencias de la crisis económica reciente (2008) sobre la credibilidad de los gobiernos y las recientes protestas sociales de los jóvenes y otros sectores afectados en Europa y Estados Unidos.

Guardando las distancias del caso y sin hacer eco de las conclusiones antidemocráticas a las que arribó la Comisión Trilateral, hoy -en prácticamente todo el mundo- se habla de nuevo de la crisis de gobernabilidad, de la discordancia o incompatibilidad entre representatividad y eficacia, de la deslegitimación de las formas de autoridad política y de la incapacidad de los gobiernos democráticos para responder a la multiplicidad de demandas que reciben por parte de la sociedad.

México no es la excepción. En el debate público de los últimos años ha tomado fuerza una posición que responsabiliza al diseño del sistema político prácticamente de todos los males que aquejan a nuestra democracia: desde el bajo aprecio que muestra la ciudadanía por esta forma de gobierno, pasando por el desprestigio de las instituciones y de la clase política, hasta la falta de acuerdos para aprobar las reformas que llevarían a México a la prosperidad. El diagnóstico revela un gran consenso: el funcionamiento de la democracia es deficitario y se ha traducido tanto en el bajo aprecio al régimen democrático, como a las instituciones que lo encarnan y a la clase política que las encabeza.

El último reporte de Latinobarómetro (2011) indica que el mexicano es uno de los sistemas democráticos menos apoyados por su población. Mientras que la media latinoamericana de apoyo a la democracia es de $58 \%$ la de México apenas alcanza $40 \%$.

De la misma manera, los más recientes estudios de medición sobre confianza en las instituciones públicas indican que éstas reciben una calificación apenas aprobatoria (alrededor de 6) y que sólo un bajísimo porcentaje de la población "confía mucho" en ellas: senadores (7\%), diputados (6\%), partidos políticos (7\%) (Consulta Mitofsky, Confianza en las Instituciones, Agosto de 2012).

A ello se añade una percepción generalizada de que ni el Estado cumple con su tarea de proveer seguridad, legalidad, incentivos a la economía, mínimos de bienestar y oportunidades; ni los partidos con la suya de ser vehículo de la representación, del diálogo, del entendimiento y, sobre todo, de ser respetuosos de la institucionalidad. 
Frente a estos hechos, ha venido tomando fuerza una posición que comparte buena parte de la clase política, de la academia y de la opinión publicada. Una posición que responsabiliza al diseño del sistema político de la crisis de la falta de eficacia, ausencia de acuerdos para el crecimiento y bienestar de la población o, de manera más radical, de un déficit importante de gobernabilidad.

Expresado de manera sintética, la narrativa o relación causal es la siguiente:

Para que México crezca y pueda satisfacer las demandas de la población hacen falta las llamadas reformas estructurales; las reformas estructurales no avanzan porque el arreglo institucional (la estructura de la división de poderes y/o el sistema de representación) no permite llegar a acuerdos o tomarlos de manera unilateral; mientras no se altere este arreglo institucional no se podrán tomar las decisiones de política pública adecuadas de manera ágil y oportuna para enfrentar los verdaderos retos del país; luego entonces, la reforma política es la madre de todas las reformas. Puesto de otra manera, la visión dominante es que el sistema presidencial mexicano "está agotado" y que es necesario hacer una revisión profunda del arreglo institucional para que funcione de manera más adecuada.

Del diagnóstico compartido se desprenden propuestas que van desde el cambio de régimen - hacia uno de carácter parlamentario o semi-presidencial- hasta una variedad de propuestas más o menos integradas que buscan alterar la división de poderes o bien la fórmula de representación para propiciar la formación de mayorías.

Sin negar que el sistema político requiere de ajustes importantes y que México podría beneficiarse de su reforma, planteo la tesis de que situar las esperanzas de solución a los problemas de funcionalidad de la democracia mexicana en el entramado institucional es errar el punto y que tiene como consecuencia elevar las expectativas sobre lo que realmente pueden ofrecer una reforma electoral o, incluso, una reforma política. ${ }^{2}$

Encuentro en las tesis dominantes dos errores de concepción. El primero es confundir el proceso de toma de decisiones - cualquiera

2 Para una revisión más detallada de estos argumentos véase Casar, María Amparo, La otra reforma, Documento de Trabajo de la División de Administración Pública del Centro de Investigación y Docencia Económicas (CIDE), México, 2009; id., "El equilibrio de poderes entre presidente y Congreso", en Negretto, Gabriel L., Debatiendo la Reforma Política, claves del cambio institucional en México, CIDE, México, 2010. 
que este sea- con las decisiones mismas. Los mecanismos institucionales establecidos para la toma de decisiones pueden ser más o menos eficaces, pueden involucrar una o más voluntades, pueden o no tener plazos perentorios, pero no determinan lo "acertado" de una política pública en términos de la correspondencia entre el objetivo deseado y su consecución. Si bien se pueden diseñar mecanismos más o menos expeditos para la toma de decisiones - las reglas de mayoría en una democracia, las áreas de traslape entre los poderes y el número de puntos de veto contemplados son algunos de ellos- su diseño tiene un impacto reducido en los resultados concretos de las políticas públicas elegidas.

El segundo error - vinculado con el anterior- es plantear la existencia de una contradicción, oposición o dualidad entre representatividad y eficacia. Los estudios de política comparada muestran que el desempeño económico, las políticas de bienestar o la equidad — por sólo citar algunos ejemplos- no encuentran correlación con el mayor o menor grado de representatividad de un sistema, en particular, con la presencia de sistemas de representación de mayoría o de proporcionalidad. Si revisamos la experiencia de México y de otros países presidencialistas, no hay evidencia alguna para sostener que hace falta restringir o reducir la representatividad para acceder a una mayor eficacia en la toma de decisiones y que puede aspirarse a ambas.

Los países de América Latina combinan de manera distinta el conjunto de variables que en teoría determinan tanto la fluidez en las relaciones entre los poderes como las probabilidades de hacer efectiva la agenda presidencial que requiere de la colaboración entre el Congreso y el Ejecutivo. Encontramos países con reelección y sin ella, con amplias facultades legislativas para el ejecutivo y sin ellas, con sistemas mixtos o de representación proporcional pura, con instrumentos de democracia directa y sin ellos, con mecanismos para destrabar situaciones de crisis o sin ellos, con elecciones concurrentes o desfasadas y, sin embargo, las tasas de aprobación legislativa y las relaciones entre poderes no muestran grandes diferencias. ${ }^{3}$

En suma, el planteamiento es que la tesis dominante es simplista y reduccionista. Simplista porque la evidencia demuestra que tener una

3 Casar, "El equilibrio de poderes entre Presidente y Congreso", cit. 
mayoría ${ }^{4}$ u otorgar facultades extraordinarias a los ejecutivos no es condición necesaria ni mucho menos garantiza que se tomen las medidas adecuadas para salir del estancamiento económico, para acelerar el crecimiento, para disminuir la pobreza o para alcanzar mayores niveles de equidad. Que el desempeño económico — que explica buena parte del desencanto con la democracia- no está sustantivamente en función de los arreglos institucionales. Reduccionista porque sujeta la eficacia o funcionalidad de la democracia a una sola variable.

Con base en los argumentos anteriores se sugiere una dosis de escepticismo en torno a la argumentación de que los problemas enfrentados por la democracia y su solución se encuentren en el diseño de nuestros arreglos institucionales. Con ello no se niega la tesis de que las instituciones tienen consecuencias políticas, sino simplemente que éstas tienen límites en su impacto sobre las políticas públicas a elegir.

Frente a la tesis de que los retos de la gobernabilidad están en un entramado institucional defectuoso propongo una interpretación alternativa que consta de tres planteamientos sobre los que debería centrarse el debate público. Los tres parten el supuesto de que ningún marco institucional puede suplir lo que la política — los políticos en el ejercicio del poder - tiene que hacer. Toda sociedad compleja y plural está caracterizada por la diversidad y conflicto de intereses y precisamente para ello está la política en un contexto democrático.

Primer planteamiento. Se refiere al dilema entre la norma y la institución. En México se ha apostado demasiado tiempo a las reformas legales en lugar de al fortalecimiento de las instituciones. El intenso

4 a) El PRI tuvo mayorías extraordinarias durante décadas y sin embargo las llamadas reformas estructurales no fueron aprobadas. b) El argumento de que los gobiernos divididos impiden el paso de reformas es cuestionable. De 1997 a 2010 he podido registrar 57 dictámenes de reforma constitucional que incluyen el cambio de 121 artículos constitucionales. En el periodo anterior -13 años de gobiernos unificados, esto es, de 1984 a 1997- registro 33 dictámenes constitucionales y 140 artículos constitucionales. c) La política comparada muestra que la mayoría de los países presidenciales avanzan en sus reformas con gobiernos divididos. Pongo dos ejemplos. Durante los cuatro últimos periodos presidenciales Brasil ha tenido Congresos extremadamente fragmentados y sin embargo la clase política (o el liderazgo presidencial) ha sido capaz de implementar las reformas necesarias. De 1953 a la fecha en Estados Unidos ha habido 15 gobiernos de los cuales 7 han sido unificados y 8 divididos y ha quedado demostrado que no hay diferencias sensibles en el trabajo legislativo y en la eficacia de la agenda gubernamental durante uno y otro tipo de gobiernos. 
reformismo desplegado en el Congreso revela una concepción que sitúa la solución a los problemas estructurales de la economía y la sociedad en la transformación de los marcos normativos - constitucionales y legales - ignorando las capacidades institucionales para ponerlas en práctica y hacerlas valer. Se promulgó una reforma municipal en 1985 pero poco se hizo en materia de la formación de capacidades administrativas para que los cuadros municipales pudieran asumir sus responsabilidades. Se impuso a los gobiernos estatales la creación de órganos electorales, de transparencia y de derechos humanos pero se permitió que los gobernadores los capturaran. Se llevó a cabo una reforma importante en materia de seguridad y justicia pero no se trabajó simultáneamente en la transformación de las instituciones para que los delitos se investigaran, persiguieran y castigaran con mediana eficacia. Se crearon órganos de autonomía técnica y, o bien no se les dotó de los instrumentos y poder sancionador para que llevaran a cabo sus funciones o se permitió que fueran penetrados por los propios sectores a los que pretendían regular. Se establecieron las condiciones de pluralidad para la actuación independiente del Congreso pero no se le fortaleció haciendo crecer sus cuerpos profesionales apartidistas. Se ha expandido la libertad de expresión pero no se cuidaron los canales a través de los cuales hacerla efectiva.

A estos ejemplos puede añadirse el de la reforma electoral de 2007 que amplió la regulación sobre los actores de la competencia y el catálogo de faltas administrativas y delitos electorales pero, en muchos casos, dejó al Instituto Federal Electoral sin los instrumentos para hacer efectivo el derecho de réplica, la sustanciación de procedimientos en contra de las radiodifusoras, la investigación de presuntas conductas violatorias de la normatividad electoral o para una fiscalización oportuna y eficaz de los gastos de campaña.

Segundo planteamiento. Se refiere a la concentración exclusiva en las reformas a los poderes formales sin ocuparse de los poderes reales.

Los proponentes de una reforma política entendida como una transformación del marco institucional que rige las formas de acceso al poder y la estructura de gobierno, pasan por alto que la política y las políticas no se reducen a las instituciones formales. En particular, hacen caso omiso de los actores que influyen de manera determinante en la toma de decisiones públicas y que tienen poder de veto sobre ellas al margen de las instituciones políticas. 
En este punto resulta pertinente recordar el argumento utilizado por el profesor Dahrendorf para contrarrestar algunos de los muy conservadores cuando no reaccionarios planteamientos de la Comisión Trilateral que situaba el corazón de la crisis de gobernabilidad en los años setenta en los llamados supuestos excesos de la democracia:

Los gobiernos democráticos encuentran difícil lidiar con el poder de las instituciones extraparlamentarias que, con sus decisiones, determinan las oportunidades de vida tanto o más que las propias decisiones de los gobiernos. Estas instituciones extraparlamentarias a menudo hacen aparecer ridículo al poder gubernamental. Cuando hablo de instituciones extraparlamentarias pienso esencialmente en las dos instituciones económicas más poderosas: las grandes empresas y los grandes sindicatos. ${ }^{5}$

La transición mexicana logró democratizar y dispersar el poder que hasta entonces estaba concentrado en un solo partido; fue exitosa en acabar con el monopolio de la representación y los privilegios que ello acarreó para el poder presidencial pero no tuvo el mismo éxito en lo que a la posición e influencia de ciertos grupos de poder se refiere. Se olvidó de que del otro lado de la ecuación estaban los poderes reales y su relación con los formales. Estos poderes "transitaron la transición" intocados e intocables. Peor aún. No sólo no se les dispersó como en el caso del poder político sino que se les fortaleció y se les permitió una mayor concentración, provocando una relación con los poderes formales todavía más asimétrica que antes. Estos poderes fácticos han permanecido intactos y haciendo uso de sus recursos han logrado mantener un espacio público lleno de privilegios y, por tanto, una sociedad también llena de privilegios.

Así, pasada la transición política, el espacio público en México sigue copado por el poder de grupos que sin ninguna investidura, representación o delegación expresa tienen la fuerza para imponer, modificar o frenar decisiones que afectan el interés público. Lo paradójico es que esos grupos derivan su poder precisamente de las concesiones y privilegios otorgados a lo largo de muchas décadas por el propio Estado. Pensar que las decisiones necesarias para detonar el crecimiento, la prosperidad o la igualdad - cualesquiera que estas sean- no

5 Dahrendorf, Ralf, "Respuesta a la Trilateral (mayo 1975)", en La crisis de la democracia, p. 191. 
se toman porque el sistema no permite formar mayorías o porque el presidente no tiene los suficientes instrumentos para hacerlo es francamente obviar la realidad. Si las decisiones para cambiar el status quo han dejado de tomarse no es por las fallas del sistema político o por un marco institucional defectuoso sino porque no ha estado en el interés de las fuerzas políticas tomarlas; porque piensan que la situación actual las beneficia o que su transformación les perjudicaría política o electoralmente.

Por eso más allá de la necesidad de una reforma política que siga transformando el poder de jure hace falta una que transforme el poder de facto. Más que una reforma política lo que hace falta es una reforma del poder.

Tercer planteamiento. Así como en biología hay una discusión entre naturaleza y crianza (genética y ambiente o nature versus nurture), en la sociología y la ciencia política hay una entre institución y cultura $\mathrm{o}$, si se quiere entre norma y práctica política. Es cierto que las instituciones arrojan incentivos para cambiar conductas pero sin una vocación y educación democráticas es poco lo que puede hacerse. Decía Montesquieu con razón: "Cuando se quieren alterar las costumbres no cabe hacerlo por medio de leyes". Decía también: "Las leyes se establecen, las costumbres se inspiran".

En el ejercicio del poder, las prácticas políticas se convierten en potentes restricciones a la eficacia en la toma de decisiones.

La transición a la democracia primero y la alternancia después, pusieron en evidencia un abanico de vicios que se resisten a morir o que en el mejor de los casos, como los virus, mutan pero no desaparecen. Ninguno de éstos se curan con el solo efecto de las leyes y todos ellos atentan - mucho más que los arreglos institucionales - contra la funcionalidad/efectividad/gobernabilidad de la democracia.

El vicio de la unanimidad: la idea de que una ley o decisión debe concitar la aprobación de todos y no sólo de la mayoría para ser legítima. Al menos, la idea de que una ley aprobada por unanimidad es mejor y más legítima que una ley que no lo es.

Los políticos y las organizaciones sociales no acaban de aceptar la regla básica de la democracia, la regla de la mayoría cuyo límite imprescindible es no atropellar los derechos fundamentales y salvaguardar los derechos de las minorías. 
No se asume a cabalidad que el método democrático consiste en que si después de un debate plural, una exposición de motivos y una argumentación sobre las consecuencias positivas o negativas de una política pública no se llega a un acuerdo, las posturas se someten a votación y prevalece aquella que es mayoritaria. No se acepta la idea de que en democracia, las decisiones tomadas por mayoría - sin importar el tamaño de esa mayoría - son tan válidas, legítimas y vinculantes como las decisiones que se toman por unanimidad y que de hecho ésta suele ser la excepción más que la regla en cualquier democracia.

Este vicio que induce a "subir a todos al carro" encarece enormemente las negociaciones y no pocas veces desfigura los propósitos de una iniciativa hasta dejarla irreconocible. A este vicio se le debe en buena medida la ineficacia de nuestra democracia.

Al vicio de la unanimidad lo acompaña el vicio de los derechos adquiridos que se quiere disfrazar de revolucionario y democrático pero que en cambio es conservador. No importa si las condiciones son otras, si ya no hay justificación para mantener una dispensa, si se va en detrimento de un sistema más claro y transparente o si hay nueva evidencia para cambiar el status quo. Lo que se otorgó no se puede quitar porque eso es despojar, saquear, expropiar. Este vicio ataca lo mismo a la política que a la economía: ahí está la no-reelección, el ambulantaje, la edad de jubilación, las exenciones fiscales, las concesiones o la cláusula de exclusión sindical. En realidad se confunden los derechos con los privilegios. Estos últimos son, a diferencia de los primeros, concesiones especiales, regalías, dispensas o, incluso, inmunidades en el sentido de estatus que sitúa a una persona o cuerpo más allá de la ley.

El tercero es el vicio del proteccionismo. Está bien otorgar condiciones favorables o conceder un periodo de gracia a los partidos, empresas, instituciones educativas, patentes o avances tecnológicos mientras crecen y se desarrollan pero, pasado cierto tiempo, tienen que ser capaces de competir sin esa protección. La protección atenta contra la competencia, acaba por ser ineficiente, milita en contra del consumidor - ya sea de bienes políticos o económicos - y provoca el estancamiento. México sabe bien de este vicio. En México se sigue protegiendo a los líderes sindicales de la disidencia y de los agremiados, a los gobernantes de la justicia, a los empresarios de otros empresarios, a los partidos de los ciudadanos. 
A ellos se une el vicio del rentismo. Vivimos y nos gusta vivir de las rentas: sindicales, contractuales, petroleras, tarifarias, monetarias. La renta toma diferentes formas. La obvia es la renta monopólica que deriva de las barreras a la entrada a un sector o actividad económica. Pero hay otros tipos de renta como las que disfrutan los trabajadores sindicalizados de sobresueldos o empleos superfluos pactados en los contratos colectivos, rentas que derivan del "coyotaje" practicado por las burocracias gubernamentales y rentas extraídas por el cobro de comisiones.

Prevalece la idea de extraer valor no a través de la productividad, de un descubrimiento o del trabajo sino a través de la renta que deriva de un recurso natural, de una concesión, de un privilegio, una tarifa preferencial o un contrato colectivo. Todas éstas legales porque fueron otorgadas por la autoridad pero a ellas se unen las ilegales que también producen rentas cuantiosas: el crimen, la evasión de la ley, el cabildeo, la captura de organismos regulatorios, la corrupción.

Se mantiene también el vicio del juicio ideológico que a pesar de vivir en democracia y pluralidad no logra ser sustituido por la virtud del debate razonado. Demasiado a menudo la discusión pública - incluida la parlamentaria- y la toma de decisiones se zanja a través de la descalificación ideológica y la glorificación del pasado sin importar las consecuencias.

Finalmente sigue presente el vicio del decretismo. La idea de que las cosas cambian radicalmente como consecuencia de decretar una ley, de que la realidad se transforma y se adapta a la ley por el solo efecto de ser promulgada. Así, se multiplican los derechos en la Constitución, se instauran órganos autónomos, se endurecen los castigos, se crean comisiones de investigación y se elaboran leyes de vanguardia. Se olvida que como decía Cosío Villegas, "el mexicano posee un enorme talento para idear y redactar leyes y un ingenio inagotable para violar las leyes que inventa”. Quizá este vicio es el que explica las más de 500 reformas a la Constitución en menos de cien años. Se tiende a olvidar que toda transacción descansa en un contrato de carácter implícito o explícito y que todo contrato requiere de su cumplimiento voluntario en primera instancia $y$, en ausencia de ese cumplimiento lo que procede es hacer valer la ley en lugar de negociarla. Persiste, arraigada en la costumbre política, un problema de tolerancia extrema con la transgresión de las leyes. 
Estos vicios que se forjaron y asentaron en la larga época en la que México carecía de un sistema democrático, gozan de plena salud y se adivinan en todo asunto de la política mexicana. Son estos vicios mucho más que el marco institucional los que se constituyen en obstáculos para el cambio y para un ejercicio democrático del poder.

De la argumentación anterior se deduce que los retos de la gobernabilidad democrática se encuentran en el hecho de que hemos acogido solo un lado de la ecuación de los dilemas planteados. Se ha atendido las normas pero no las instituciones, los poderes formales pero no reales y la pluralidad pero no la responsabilidad que conlleva.

Dados estos vicios y los tres planteamientos expuestos, se deriva la propuesta de hacer una lectura crítica de los años que México ha vivido en democracia e intentar extraer algunas lecciones. A manera de conclusión, a continuación se presentan algunas de ellas: ${ }^{6}$

Primera lección. La democracia no es necesariamente eficaz. Una cosa es que las políticas públicas se tengan que resolver en democracia y otra que la democracia produzca políticas que conduzcan al progreso. Los gobiernos que emanan de elecciones democráticas pueden ser: ineficientes e incapaces, corruptos e irresponsables, cortos de miras y dominados por intereses particulares. Pueden producir políticas públicas que conduzcan a la prosperidad, justicia y equidad pero también políticas públicas que reproduzcan el estancamiento, la pobreza y la desigualdad.

Las buenas políticas públicas no pueden decretarse a través de un buen sistema de representación ni a través de un marco adecuado de división de poderes.

Segunda lección. Ninguna forma de gobierno o arreglo político es a prueba de los hombres que pueblan sus instituciones. Las instituciones pueden diseñarse con todo cuidado y con toda precisión pero siempre son habitadas y operadas por un pequeño universo de personas elegidas y designadas por un universo mayor de personas. Si no se actúa sobre ellos, sobre sus usos y costumbres, difícilmente las instituciones podrán desplegar su potencial. De aquí la necesidad de ampliar las capacidades democráticas de gobernantes y gobernados.

6 Véase Casar, Ma. Amparo y González, Guadalupe, El juicio del siglo, México, Taurus, 2010 . 
En este sentido, los marcos institucionales importan pero por sí solos no alcanzan para determinar los resultados. Si revisamos las experiencias de América Latina lo que vamos a encontrar son países con arquitecturas políticas muy similares que arrojan desempeños muy distintos en términos de acuerdos, de legitimidad de sus gobernantes y de aprecio por sus instituciones. Tenemos ejemplos de multipartidismos en los que se logran acuerdos y bipartidismos en los que no, tenemos ejemplos con segunda vuelta en los que los presidentes resultan un desastre y tenemos países con reelección en los que los legisladores están lejos de rendir cuentas.

Tercera lección. La democracia va más allá de tener una representación plural; es una ecuación que tiene dos lados. Conlleva y exige no sólo la representación plural sino la cooperación entre los integrantes de esa pluralidad, no sólo la autonomía de los Estados sino su responsabilidad, no sólo la clara delimitación entre las facultades de las ramas de gobierno sino su colaboración, no sólo el establecimiento de nuevas reglas de la competencia sino la disposición a respetarlas, no sólo la creación de órganos autónomos sino el compromiso de no capturarlos y acogerse a sus decisiones. En México se han puesto en práctica las primeras pero no las segundas.

Cuarta lección. El consenso entre las élites es indispensable. Con espacio para su perfeccionamiento México tiene un arreglo institucional democrático y funcional, lo que no se ve son las ganas de mover las voluntades política y social hacia un objetivo común. El peor de los problemas es la ausencia de un consenso para dar tregua a los conflictos políticos y hacer un pacto social sobre bases nuevas que tengan un propósito común: crear riqueza y distribuirla lo más equitativamente posible tanto en el lado de las oportunidades como en la de los recursos. Este pacto involucra tanto a las élites políticas como a las económicas.

Quinta lección. Los privilegios ahogan el progreso. La estabilidad lograda no ha sido ajena a las dádivas y concesiones. Se creó lo que hace muchos años se llamó la república del subsidio y junto con ella la república de los privilegios. Los años de estabilidad pactada a base de cooptación por la vía de concesiones están resultando inadmisiblemente costosos. Seguimos siendo un país de fueros y privilegios y no uno de igualdad ante la ley. 
Sexta lección. La democracia tiene mayor oportunidad de sobrevivir mientras más elevado sea el PIB per cápita; éste es el principal componente para la consolidación de las democracias.

La discusión sobre la relación entre economía y política no ha sido resuelta, pero existen algunas regularidades. Una de ellas es que la probabilidad de que las democracias sobrevivan y se consoliden está relacionada con el grado de desarrollo económico de las naciones y con la prevalencia del Estado de derecho.

Por eso si de apostar por uno u otro conjunto de reformas se tratara, habría que apostar por aquellas reformas que lleven al crecimiento económico y al fortalecimiento de la legalidad. Son las dos vías más seguras para acabar con los déficits sociales y, con ello, apuntalar la consolidación democrática.

El problema entonces es que la democracia está íntimamente vinculada con la prosperidad pero no la produce. Cada una corre por cuerdas separadas.

El reto es demostrar que en democracia se pueden producir políticas públicas consistentes y adecuadas - políticas que conduzcan a la prosperidad y a la menor desigualdad-y constatar que estas políticas son el mejor camino para consolidar el aprecio por la democracia. 